YOL. VI, FASC. 1 E 2, P. 143.151

\author{
Bomolochus xenomelanirisi n. sp. PARASITO \\ DE PEIXE-REI - Xenomelaniris brasiliensis (Quoy \& Gaimard) \\ (COPEPODA - CYCLOPOIDA - PISCES - MUGILOIDEI)
}

(RECEBIDO $20 / \mathrm{V} 11 / 55)$

J. de Paiva Carvalho (*)

Wilson (1911, p. 374-375, est. 56, fig. 177-183) descreveu um Copépodo que, na ocasião, considerou como fazendo parte da família Ergasilidae, por êle encontrado em 1905 (Beaufort, Carolina do Norte) nas brânquias de uma tainha - Mugil cephalus (L.) - a que deu a denominação específica de Bomolochus nitidus. Pela mesma época (1.c., p. 377-378, est. 58, fig. 191-201), descreveu também, B.exilipes, encontrado como hóspede de um sargo - Archosargus probatocephalus (Walbaum). Referindo-se à primeira espécie, diz o autor (p. 375): "...êsses parasitos não são muito comuns, pois o exame de várias centenas de peixes só revelou a presença de dois indivíduos." Quanto à segunda, informa (p. 378) que ela é "muito comum", acrescentando que os 15 exemplares que havia examinado nas coleções do Museu Nacional dos Estados Unidos, haviam sido retirados de sargos.

Nas águas do Atlántico Sul brasileiro, o gênero Bomolochus não parece ser dos melhores representados. Em 1952, sob os auspícios do Conselho Nacional de Pesquisas, do Rio de Janeiro, tivemos ocasião de examinar 100 exemplares de Peixe-Rei, no litoral sul do Estado

(*) - Trabalho executado sob os auspícios do Conselho Nacional de Pesquisas do Rio de Janeiro. 
de S.Paulo, dos quais obtivemos 572 copépodos ecto-parasitos pertencentes à Subordem Cyclopoida, sendo 543 do gênero Ergasilus e sòmente 56 do gênero Bomolochus. 0 exame dêstes, revelou a presença de caracteres comuns às duas espécies acima citadas, delas diferindo, no entretanto, por peculiaridades que serão apontadas na diagnose respectiva.

A primeira consequência decorrente do estudo aqui realizado consiste na constatação da necessidade urgente que há de se promover uma revisão cuidadosa do gênero Bomolochus, não tanto porque a chave de Wilson apresente lacunas e contradições, mas, subretudo, por já se ter tornado obsoleta. De fato, basta considerar, no momento, o fato de Stock (1953, p. 5-7) ter descrito B.confusus, baseado em material que já havia sido manipulado por autores inglêses e norte-americanos e cujos representantes foram considerados como B.solae. As considerações do mesmo autor (p. 11-12) a respeito do status do gênero Artacolax Wilson 1908, são também dignas de tôda a atenção. Êste, porém, não é o momento oportuno para a discussão do assunto, pelo que nos limitaremos a fornecer as características da espécie que consideramos como nova.

Agradecemos ao Conselho Nacional de Pesquisas, do Rio de Janeiro, os recursos fornecidos para a execução do presente trabalho.

Bomolochus xenomelanirisi $\mathrm{n}$. sp.

$$
\text { (Est. I, Fig. 1-13) }
$$

\section{$F \hat{E} M E A$}

COORRÊNCIA - 30 OQ extraídas de um lote de 100 exemplares de Feixe-Rei - Xenomelaniris brasiliensis (Q. \& G.), capturados em Cananéia (litoral sul do Estado de S.Paulo) entre os meses de janeiro a junho de 1952.

TIPO - Q medindo $1,5 \mathrm{~mm}$ (sem as setas caudais). Lâmina $\mathrm{n}^{\circ} 1.347$, da col. da Seç̧ão de Oceanografia Biológica (13-3-952).

C-TIPOS - $Q$ Q medindo 1,6 e 1,7mm. Lâmina n 1.348 (13-3-52).

TOPO-TIPOS - $Q$ Q medindo 1,3 e 1, 4mm. Lâmina n $1.349 ; 1,5$ e 1,6mm. Lâmina $\mathrm{n}^{\circ} 1.350$ (15-1-54), respectivamente.

DESCRIÇÃo - Cefalotórax (Est. I, Fig. 1) semi-el íptico, um pouco mais comprido do que largo, com o têrço anterior bem saliente 
na face dorsal, formando giba; porções laterais dos segmentos com cantos arredondados. Todos os segmentos são mais largos do que compridos. Placa frontal (Est. I, Fig. 8), em forma de funil; a margem frontal encobre, em parte, as bases das antênulas, quando se observa o exemplar no plano dorsal; segmentos toráxicos livres, diminuindo gradativamente de largura, da porção anterior para a posterior. Primeiro segmento, fundido com a cabeça, seu comprimentr sendo igual ao do segundo e terceiro reunidos; segundo segmento, de comprimento pouco inferior ao da metade do primeiro; terceiro segmento mais comprido do que o segundo; quarto segmento muito estreito, ficando quase sempre encoberto pela aba do terceiro segmento; quinto segmento projetando-se fortemente para os lados, na base do quinto par de pernas, exibindo a mesma largura e comprimento que o quarto segmento; sexto segmento com a porção mediana lateral entumescida.

Abdomen (Est. I, Fig. 12) segmentado, com os artículos respectivos diminuindo gradativamente de tamanho em direção às lâminas caudais, sendo o terminal um pouco mais comprido. Lâminas caudais, de comprimento quase igual ao do último artículo abdominal, cada uma com cinco setas assim distribuidas: - uma, na porção lateral mediana; - outra, na face dorsal posterior e as demais na região terminal; a maior das duas setas terminais é a interna.

Sacos ovígeros cil ́́ndricos, compridos e largos, mais volumosos nas proximidades do segmento genital, quase do mesmo tamanho dos segnentos livres e contendo, cada um, de 120 a 150 ovos.

Antênulas (Est. I, Fig. 4) robustas, mais ou menos longas, o artículo terminal mais fino e alongado, ultrapassando bastante a orla lateral da carapaça. São providas de numerosas cerdız robustas e arqueadas, particularmente abundantes no segmento basal. As antênulas possuem 5 segmentos, o basal curto, robusto e alargado; os demais conservam as características peculiares ao gênero. Antenas (Est. I, Fig. 13-A), também típicas, exibem o artículo mediano densamente provido de carreiras de espículas, sendo que a porção superior possue espículas maiores, mais numerosas e muito unidas, como os dentes de um pente. O áftimo artículo termina com um processo digitiforme, espinhoso e cinco garras robustas, encurvadas, quase do mesmo tamanho.

Labrum (Est. I, Fig. 11), em forma de escudo, mais comprido do que largo, com estrias sinuosas que descem dos cantos laterais superiores, em direção ao centro; possue uma goteira mediana bci. nítida. 
Primeira maxila (Est. I, Fig. 13-MX1) representada por excrecência munida de 4 setas divergentes, duas das quais sensìvelmente mais grossas e algo mais longas, tôdas fortemente pilosas. A julgar pelo trabalho de Stock (l.c., p. 2, fig. 5), a primeira maxila de B. solae é dotada de 4 setas, duas das quais são muito menores do que as da espécie ora descrita.

Segunda maxila (Est. I, Fig. 13-MX2), com artículo basal grande e robusto, a porção terminal divergente ou bipartida, com ponta acuminada e ramos pilosos.

Maxilipodos (Est. I, Fig. 13-MXP), situados fora da região em que se encontram as demais peças bucais; artículo terminal fundido com a cabeça. São de bom tamanho, robustos, fortemente encurvados nos ângulos e dotados de grosso e curvo dente acessório, situado na porção média da margem externa. Possue uma seta plumosa, no ângulo interno superior e outra, bem mais longa, mais grossa e fracamente pilosa, que se origina no mesmo ângulo e cuja ponta ruma em direção à segunda maxila.

Mandíbula (Est. I, Fig. 13-MD), simples e lisa, exibindo na porção distal inferior, uma formação pilosa que lembra a de uma escova, sem qualquer formação secundária no segundo artículo.

Primeira perna (Est. I, Fig. 7), com exopodito uni-articulado, de formato mais ou menos triangular, margem posterior armada com 6 setas fortes, plumosas, com a base alargada, a mais anterior com um espinino sólido, de ponta algo recurvada. Endopodito bi-articulado, o primeiro e o segundo artículos exibindo uma seta robusta e pilosa; terceiro artículo com cinco setas idênticas. A primeira perna é muito semelhante a de B.nitidus, dela diferindo apenas em pequenos detalhes. Segunda perna (Est. I, Fig. 6), com exopodito bi-articulado; primeiro artículo com seta grossa, encurvada e plumosa, tendo na base uma entumescência; segundo artículo com duas setas semelhantes às anteriores e um processo espatuliforme e piloso; terceiro artículo com 3 setas e 2 dentes, pequenos, de ponta lancetiforme, lembrando muito o orgão quase idêntico de B.exilipes. Terceira perna (Est. I, Fig. 5), com exopodito quadri-articulado: o primeiro, com um dente externo, o segundo com um externo e outro interno, o terceiro sòmente com um externo e o quarto com um externo e seis setas plumosas. Endopodito bi-articulado, com o primeiro e o segundo artículos dotados, cada um, de uma seta plumosa; terceiro artículo com duas setas, idênticas e dois dentes pequenos, pontudos e ligeiramente encurvados. Quarta perna (Est. I, Fig. 9), típica do gênero. Quinta perna (Est. I, Fig. 10) não 
diferindo muito da de B.exilipes, com artículo basal mais comprido e o dente mediano do artículo terminal situado mais lateralmente.

Os acúleos constantes da primeira, segunda, terceira e quarta pernas, possuem um pequeno apêndice secundário que se destaca da extremidade de processos análogos de B.nitidus, da 4a. perna de B. solae e das 2a., 3a. e 4 a. pernas de B.teres, havendo ainda no dorso dos referidos acúleos, uma serrilha que ocupa quase tôda a sua extensão (Est. I, Fig. 5a).

Existem rudimentos do sexto par de pernas, representados por pequenas papilas situadas ao lado das aberturas dos ovidutos, das quais partem setas delgadas e não pilosas.

Nos exemplares vivos, o colorido é branco ou creme, sem qualquer pigmentação, mas o dorso é provido de esculturações opacas.

\section{A C HO}

OCORRÊNCIA - 14 indivíduos aderentes aos segmentos genitais das fêmeas, das quais, uma delas, possuia dois machos.

TIPO - O medindo $0,7 \mathrm{~mm}$ (sem as setas caudais). Lâmina $\mathrm{n}^{\circ} 417$, da col. da Seç̧ão de Oceanografia Biológica (25-4-1952).

CO-TIPOS - ర ర $\sigma^{*}$ medindo 0,8;0,7;0,7mm. Lâminas n० 418 (7-8-52) n० 419 (16-5-52), n० $420(20-3-53), n^{\circ} 422(18-6-52)$, respectivamente.

TOPO-TIPOS - $0^{*} 0^{*}$ medindo 0,$7 ; 0,7 \mathrm{~mm}$. Lâmina n० 423 (25-4-52), n० 424 (18-6-952), respectivamente.

DEscrição - Corpo ciclopoidal (Est. II, Fig. 8). Urosoma tri- segmentado. Tamanho muito inferior ao da fêmea, medindo sempre menos de 3 a 4 vêzes o tamanho dela. Primeiro segmento com a porção anterior arredondada e a posterior reta; como na $Q$, êsse segmento encontra-se fundido com a cabeça. Antênula (Est. II, Fig. 1) com seis segmentos, todos providos de cerdas, existindo 5 maiores e 2 menores no segmento basal. Antena (Est. II, Fig. 2), quase iqual à da fêmea, comuma franja muito pilosa na porção superior do artículo mediano. Segundo maxil ípodo (Est. II, Fig. 2) forte, com o segmento basal alongado, o mediano robusto e armado com um dente aguçado na margem interna e dentículos distribuidos também ao longo e nas proximidades da orla interior; artículo terminal representado por um gancho longo, delgado, de ponta recurvada e com a margem interna crenulada. 
Primeira perna (Est. II, Fig. 4) com basipodito espinhoso na face mais interna e piloso na orla superior e inferior; endopodito e exopodito tri-segmentados. As demais pernas são como na fêmea, inclusive a quinta, cujo artículo terminal é bem mais estreito e armado com dois espinhos.

Não foram observados vestigios da sexta perna. Os espinhos constantes das respectivas pernas, possuem um pequeno apêndice secundário, semelhante ao da fêmea, não nos tendo sido possível constatar a existência de qualquer serrilha.

Na região abdominal, correspondendo a cada segmento, existem 4 séries de orgãos de fixação, fortemente espinhosos. A primeira série, situada na porção posterior do primeiro segmento, é composta de uma almofada de formato mais ou menos triangular, ladeada por dois tubérculos, ambos recobertos por pequenos espinhos (Est. II, Fig. 5). As demais séries, também fortemente espinhosas, são i dên ticas.

Dı́scussão - A $Q$ de Bomolochus xenomelanirisi, aqui descrita, encontra-se entre B.nitidus Wilson e B.exilipes Wilson, aproximando-se mais daquela espécie do que desta, quanto à conformação geral do corpo e do quinto par de pernas. Distingue-se, porém, das duas espécies acima referidas: 1)- pela conformação geral do maxilípodo que, em B.xenomelanirisi, é portador de um dente lateral, recurvado e pontudo, como o de B. concinnus; al ém disso, do ângulo superior interno, partem duas setas, uma delgada e plumosa, outra fracamente pilosa, porém muito mais grossa e mais longa, que ruma em direção às segundas maxilas; 2 )- por ter a primeira maxila provida de 4 setas divergentes e plumosas, com as extremidades ligeiramente a rqueadas para cima; 3 )- por ter antênula maior, com artículo terminal ultrapassando bem a orla da carapaça; 4)- por ter antena mais fortemente armada; 5)- pela conformação dos ovisacos, havendo nêles maior número de ovos. Os rudimentos do sexto par de pernas também divergem um pouco de B.exilipes.

0 O da espécie aqui descrita, assemelha-se aos demais do gênero, aproximando-se mais do de B.solae.

DADOS ECOLÓGICOS - Em $90 \%$ dos casos, os espécimes achavam-se fixados à porção posterior interna do opérculo do hospedeiro, encontrando-se sempre envolvidos em abundante quantidade de mucor Apenas $10 \%$ dos exemplares foram encontrados sôbre os filamentos branquiais nunca a êles sòlidamente aderentes, afigurando-se-nos que para aí se dirigiram depois de terem sido os hospedeiros postos em contacto com os líquidos fixadores. 
Situado quer em um, quer em outro local, o parasito tinha sempre assegurado o mais perfeito arejamento dos ovos, tornando-se também extremamente cômoda a liberação dos nauplius.

Não foi possível averiguar nada quanto à alimentação dos parasitos. As preparações microscópicas nada revelaram no conteúdo gastro-intestinal, podendo-se admitir que só haja ingestão de muco do opérculo e, em menor porcentagem, de sangue das brânquias do hospedeiro.

Tudo parece indicar que as fêmeas nunca abandonam o local em que inicialmente se fixaram, mesmo quando se acham desprovidas de sacos ovígeros. Em geral, encontram-se mais ou menos bem fixadas, tornando-se difícil destacá-las, em virtude não sòmente dos fortes ganchos de que são possuidoras mas também à vista da configuração das abas da carapaça, que agem como ventosas, aderindo bem ao hospedeiro.

Os machos, foram sempre encontrados sòlidamente fixados ao segmento genital das fêmeas, sobretudo pelo gancho possante do segundo maxil ípodo. Sôbre êsse modo de adesão, diz Stock (1.c.,p. 5): "Compartilho da opinião de Gnanamuthu (p. 315) segundo a qual êsse meio com que o macho se fixa à fêmea ovada, parece ser comum ao gênero Bomolochus, pois nenhum dos machos até hoje conhecidos foi encontrado em estado de vida livre, mas sempre com as fêmeas, nas brânquias ou nas fossas nasaes do hospedeiro. Confronte-se também a confirmação disso com o que T. e A.Scott (1913, p. 38 tipo pequeno) dizem a respeito de B. confusus".

Em cada fêmea, encontrou-se geralmente um único macho, havendo só um caso em que foram observados dois, um na face dorsal e outro na ventral. Fora do período da procriação, acreditamos que o pequenino macho permaneça como hóspede de algum organismo bentônico, abandonando-o sòmente na época em que a fêmea está em condições de ser fecundada.

A ausência de machos, fora da época do conúbio, constitue, aliás, peculiaridade das mais frequentes em certas famílias da Subordem Cyclopoida, tanto assim que a maioria das diagnoses específicas apresenta sòmente caracteres da fêmea. Na nossa coleção de lâminas microscópicas, contamos com 13 indivíduos com um e o décimo quarto com dois machos. As preparações que contém sòmente machos, em número de nove, foram feitas depois de sua retirada dos segmentos genitais das fêmeas. Na América do Norte, até o ano de 1911, tal documentação parece ter sido extremamente pobre, a julgar pela assertiva de Wilson (1.c., p. 266) sequndo a qual, em tôda a 
coleção do Museu Nacional "...não havia sido nunca encontrado macho e fêmea em união" excetuando-se o caso de Bomolochus megaceros referido por Basett-Smith.

Retirada do hospedeiro, quando viva, a fêmea demonstra boa capacidade de movimentação; nada com relativa facilidade mas, com muita frequência, perde o equilíbrio, fica emborcada, em decúbito dorsal, demorando-se algum tempo para recuperar a posição normal. Muito mais ágil é o macho; nada velozmente, avançando por meio de impulsos rápidos e ritmados, conservando sempre o corpo em equi1 f́brio. Demonstra, assim, a capacidade que possue de se manter perfeitamente bem no ambiente planctônico.

\section{RESUMO E CONCLUSÕES}

Versa o presente trabalho sôbre uma nova espécie de crustáceo ecto-parasito do Peixe-Rei - Xenomelaniris brasiliensis (euoy \& Gaimard), Copepoda, Cyclopoida, da Subordem Caligoida.

0 material, composto de 30 \& $q$ e $14 \sigma^{\prime \prime} \sigma^{\circ}$, foi extraido de um lote de 100 representantes da família Atherinidae, capturado em frente da Base de Pesquisas que o Instituto Oceanográfico, da Universidade de S.Paulo, mantém na cidade de Cananéia (litoral sul do E. de S.Paulo). Dita amostra foi colhida entre os meses de janeiro a junho de 1952, sob os auspícios do Conselho Nacional de Pesquisas do Rio de Janeiro.

A espécie nova aqui descrita, encontra-se entre Bomolochus nitidus Wilson e B.exillipes Wilson, delas diferindo pela conformaça do maxilípodo, pelo maior número de setas da primeira maxila, pelo comprimento da antênula, pela armadura mais possante da antena e pela conformação dos sacos ovígeros.

0 autor desoreve $O^{t}$ e $O$, ilustrando o trabalho com duas estampas contendo, an todo, 21 desenhos, fornecendo também alguns dados ecol 6 gicos sốbre os mesmos.

\section{S UMMAR Y}

This work deals with Bomolochus xenomelanirisi n. sp. - Copepoda Cyclopoida - that was found as parasite on Xenomelaniris brasiliensis (anoy \& Gaimard), a fish inhabiting the south seashore region of Sâo Paulo State (Brazil).

On examining $100 \mathrm{fishes,} \mathrm{the} \mathrm{author} \mathrm{found} 30 \mathrm{Q} Q$ and $14 \sigma^{\circ} \sigma^{\prime}$, all of which were attached to the internal portion of the posterior region of the opercle.

The new species here described is related to Bomolochus nitidus and B.exilipes, both described by Wilson, but differs from them by the shape 
of the maxilliped, by the greater number of setae of the first maxilla, by the lenght of the second antennae, by the strongest armature of the first antennae and by the shape and number of the eggs contained in the ovigerous sacs.

The author describes male and female, illustrating the descriptions with 21 drawings. Some ecological notes are presented.

The author is indebted to the National Research Council (Conselho Nacional de Pesquisas) of Rio de Janeiro, for a grant in aid, for which thanks are due.

STOCK, J.H.

1953. "Bomolochus solae Claus, 1864 and B.confusus n. sp.: two hitherto confounded copepods, with remarks on some other Bomolochus species". Beaufortia, Zool. Mus. Amsterdam, no 24 , p. $1-13$.

WIL.SON, C.B.

1911. North American Parasitic Copepods belonging to the family Ergasilidae. Proc.U.S.Nat. Mus., Vol. $¥ 9$, p. $233-400$, est. $41-60$. 
E X P L I C A C ÃO D A S F I GURAS

\section{Estampa I}

Fig. 1 - Vista dorsal (exemplar medindo $1,5 \mathrm{~mm}$ )

Fig. 2 - Vista lateral

Fig. 3 - Porcão anterior da carapaca

Fig. 4 - Antênula

Fig. 5 - Terceira perna

Fig. $5 a$ - Detalhe dos acúleos das pernas

Fig. 6 - Segunda perna

Fig. 7 - Primeira perna

Fig. 8 - Placa frontal

Fig. 9 - Exododito da 4 a. perna

Fig. 10 - Ouinta perna

Fig. 11 - Labrum

Fig. 12 - Segmento genital e rudimentos da 6a. perna

Fig. 13 - Partes bucais, compreendendo:

$$
\begin{aligned}
& A \text { - Antena } \\
& M D_{\text {- Mandibula }} \\
& M X_{1} \text { - Primeira maxila } \\
& M X_{2} \text { - Segunda maxila } \\
& M X^{-} \text {- Maxilípodo } \\
& L \text { - Lábio }
\end{aligned}
$$




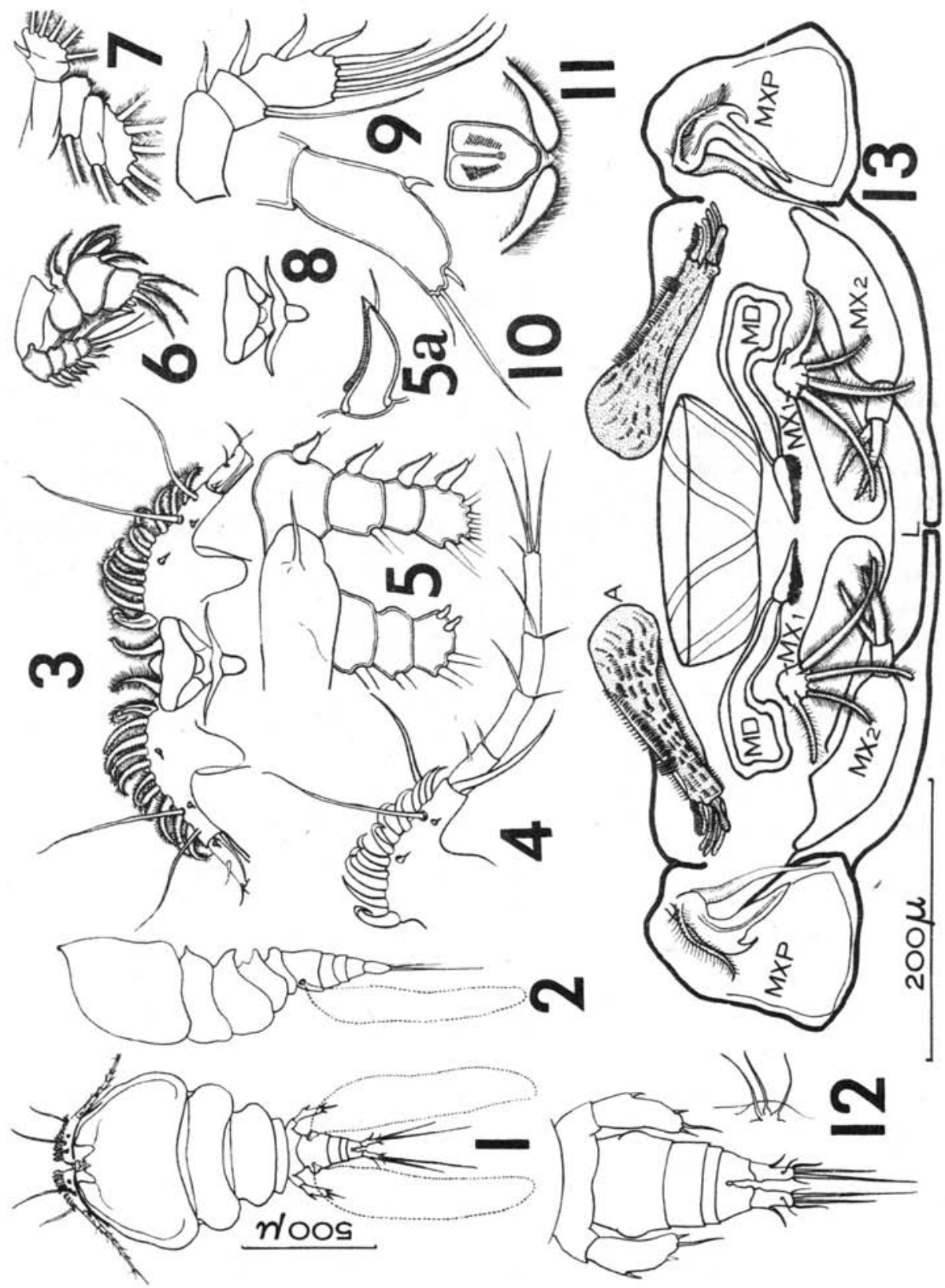


Estampa II $\delta$

Fig. 1 - Antênula

Fig. 2 - Partes bucais

Fig. 3 - Ouinta perna

Fig. 4 - Primeira perna

Fig. 5 - Vista ventral (orgãos de fixasão, fortemente aumentados, ao lado)

Fig. 6 - Maxilípodo

Fig. 7 - Antena

Fig. 8 - Vista dorsal (exemplar medindo $0.7 \mathrm{~mm}$ ) 

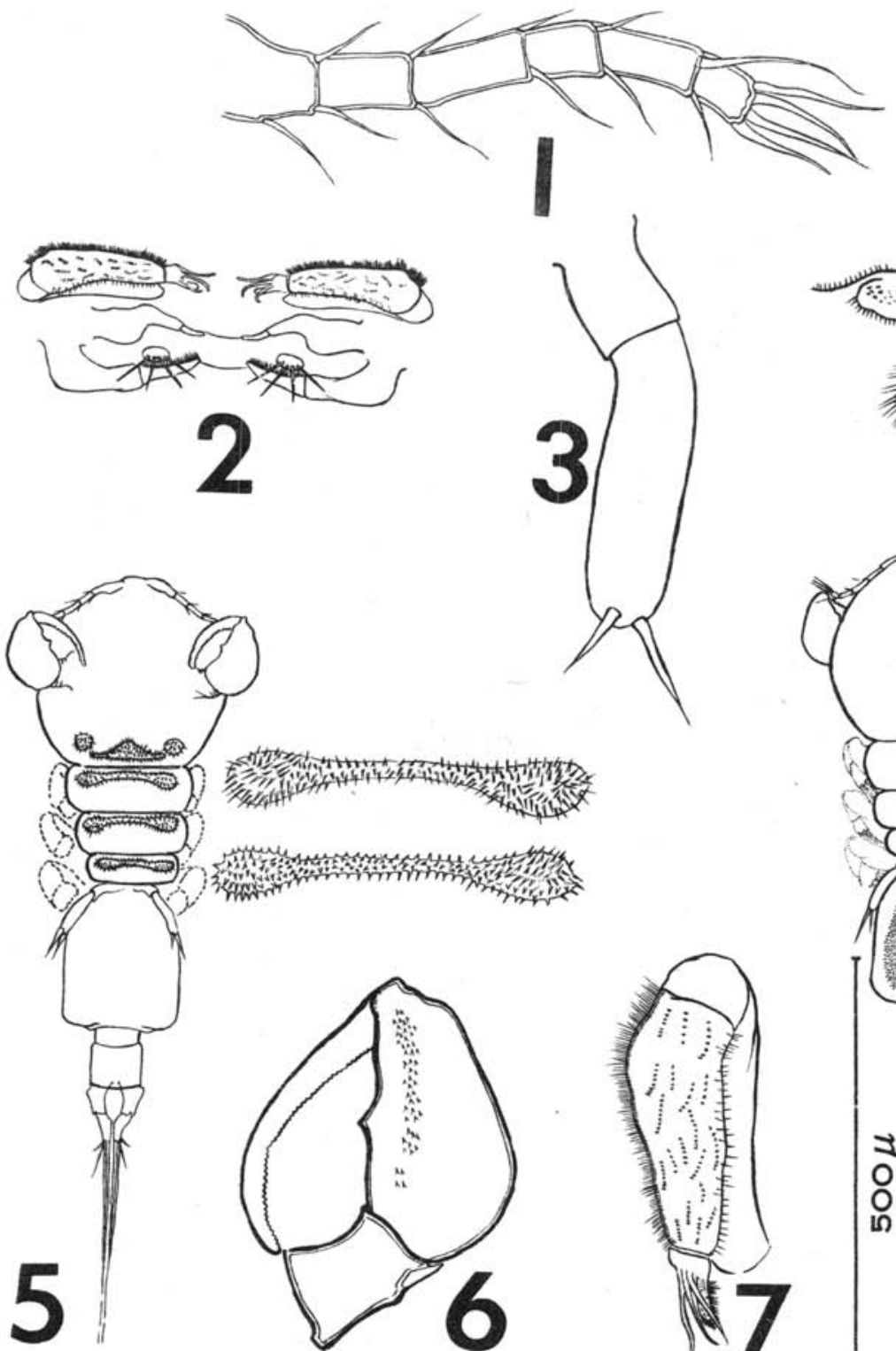

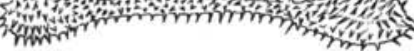
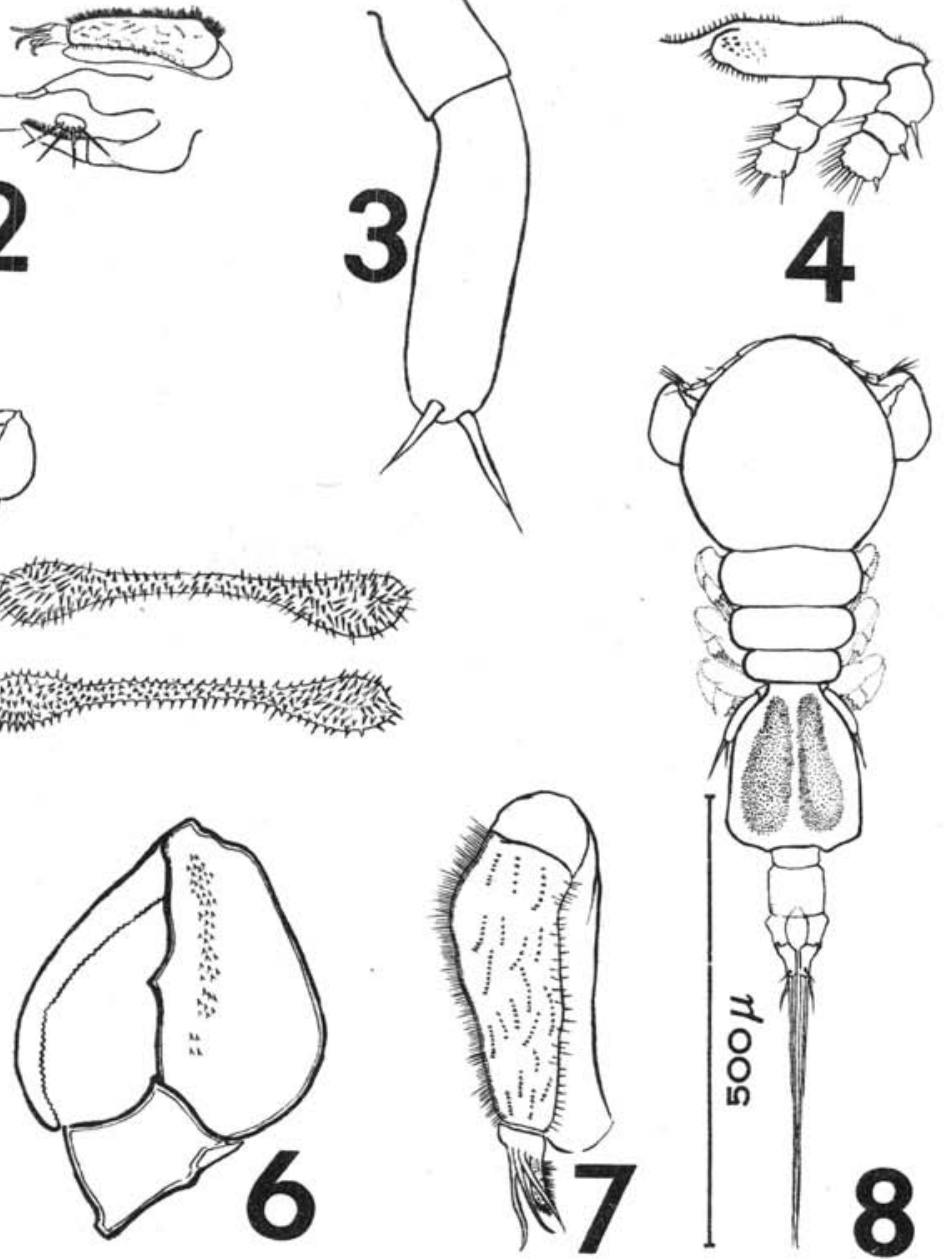